\title{
Exercise, Appetite and Appetite-Regulating Hormones: Implications for Food Intake and Weight Control
}

\author{
David Stensel \\ School of Sport, Exercise and Health Sciences, Loughborough University, Loughborough, UK
}

\section{Key Words \\ Acylated ghrelin - Exercise-induced anorexia • Ghrelin • Glucagon-like peptide $1 \cdot$ Gut hormones · Hunger • Oxyntomodulin · Peptide YY · Satiation • Satiety}

\begin{abstract}
Knowledge about the relationship between exercise and appetite is important both for athletes wishing to optimise performance and for those interested in maintaining a healthy body weight. A variety of hormones are involved in appetite regulation including both episodic hormones, which are responsive to episodes of feeding, and tonic hormones, which are important regulators of energy storage over the longer term (e.g. insulin and leptin). Notable among the episodic appetite-regulating hormones is ghrelin, which plays a unique role in stimulating appetite and energy intake. Many studies have demonstrated that acute bouts of moderately vigorous exercise transiently suppress appetite and this has been termed 'exercise-induced anorexia'. The mechanisms by which acute exercise suppresses appetite are not fully understood but may involve lowered concentrations of ghrelin and increased concentrations of satiety hormones, notably peptide $Y Y$ and glucagon-like peptide 1. Evidence suggests that chronic exercise training typically causes a partial but incomplete compensation in energy intake perhaps due to beneficial changes in appetite-regulating hormones. The
\end{abstract}

lack of a full compensatory response of appetite to exercise may facilitate the development of a negative energy balance and weight loss although there is individual variability in the response to exercise. From a practical standpoint athletes should not feel concerned that exercise will cause overeating as there is limited evidence to support this. For those desiring weight loss there may be some merit in performing exercise in the postprandial period as a means of enhancing the satiating effect of a meal but additional evidence is required to confirm the effectiveness of this strategy.

Copyright $\odot 2011$ S. Karger AG, Basel

\section{Introduction}

A good understanding of the relationship between exercise, appetite and weight management is important for sportsmen and women wishing to optimise performance in their chosen sport. It is also important for anyone interested in using exercise to maintain a healthy weight. Beyond these obvious applications knowledge in this area has relevance for those required to perform in extreme environments, e.g. athletes exercising in the heat, swimmers submerged in cold water, mountaineers exposed to high altitude conditions and military personnel who may be required to perform in a variety of hostile environments often with limited sleep. In addition, knowledge of

\section{KARGER \\ Fax +41613061234 \\ E-Mail karger@karger.ch}

www.karger.com
(C) 2011 S. Karger AG, Basel

$0250-6807 / 10 / 0576-0036 \$ 26.00 / 0$

Accessible online at:

www.karger.com/anm
Dr. David Stensel

School of Sport, Exercise and Health Sciences

Loughborough University

Loughborough, LE11 3TU (UK)

Tel. +44 1509226 344, Fax +44 1509226 301, E-Mail D.J.Stensel@lboro.ac.uk 
how exercise influences appetite may help in facilitating weight gain in those who are underweight due to disease or malnutrition. The purpose of this article is to review recent developments in this field with particular emphasis on the role of appetite-regulating hormones in moderating the interrelationships between exercise, appetite and weight management.

\section{Appetite-Regulating Hormones}

Appetite regulation is a complex process involving communication between the hypothalamus within the brain, various gastrointestinal organs (including the stomach, the pancreas, and the intestines) and adipose tissue. Satiation (the process that causes one to stop eating) may be initiated by neural input from the stomach to the brain signalling gastric distension after food consumption. This is quickly followed by the release of a variety of hormones which are able to sense the digestion and absorption of nutrients and signal satiety (the feeling of fullness that persists after eating). These hormones include cholecystokinin (secreted from the duodenum and jejunum), glucagon-like peptide 1 (GLP-1), oxyntomodulin (OXM) and peptide YY (PYY) (all secreted from the small and large intestines) and pancreatic polypeptide (PP) and amylin (both secreted from the pancreas). These hormones act as short-term or episodic signals because they occur in unison with episodes of eating. They signal satiation and satiety either via the vagus nerve (which connects the gut to the brain) or via blood perfusing the hypothalamus. In addition to these episodic hormonal signals there are also tonic hormonal signals which indicate the level of energy storage in the body. Two important tonic satiety signals are insulin (released from the pancreas) and leptin (released from adipose tissue). These hormones assist in the regulation of energy balance over the long term. For detailed explanations about how the hormones introduced here regulate appetite, the reader is referred to several recent reviews [1-4].

All of the hormones mentioned so far act to a greater or lesser extent as satiety signals, i.e. high concentrations of each hormone in the blood suppress appetite. In contrast, the gut hormone ghrelin, released predominately from the gastric cells within the stomach, is known to have appetite-stimulating properties as demonstrated in experiments where either intravenous [5] or subcutaneous [6] ghrelin infusion has led to increased ad libitum energy intake during buffet meals (for a detailed review of ghrelin metabolism, see Chen et al. [7] and Stengel et al. [8]). Recently ghrelin therapy has been found to be effective for improving appetite and food intake and limiting weight loss in patients with gastric cancer after total gastrectomy [9] confirming its function as an appetite stimulant. Ghrelin is unique as the only gut hormone known to enhance appetite and because of this there is great interest in the potential for lifestyle factors (including exercise) to modify ghrelin concentrations and assist in weight control [10].

It is important to note that the homeostatic mechanisms of appetite regulation mentioned here may be modified at times by reward pathways relating to the pleasurable qualities of food and drink. These pathways are sometimes termed hedonistic drives and in an environment characterised by an abundance of palatable foods hedonistic drives may frequently override homeostatic ones $[11,12]$. Figure 1 provides an overview of the appetite-regulating hormones described here and their potential interaction with exercise. Evidence relating to exercise and appetite-regulating hormones is discussed below.

\section{Acute Effects of Exercise on Appetite and Appetite-Regulating Hormones}

Improved understanding of the metabolism of appetite-regulating hormones has enhanced interest about the effects of exercise on appetite and whether these effects are mediated by appetite-regulating hormones. Studies have investigated the effects of exercise on appetite (the desire for food or drink) using visual analogue scales. These scales consist of a line, usually 100 or $150 \mathrm{~mm}$ long, anchored by answers to a question posed above the line, e.g. 'How hungry are you?', 'Not at all hungry' vs. 'As hungry as I have ever felt'. Scales have been devised for a variety of sensations beyond hunger including fullness, satiety, prospective food consumption (i.e. how much do you think you can eat?) and others (see Benelam [1] and Blundell et al. [13] for further details). These scales have been shown to have good reproducibility and are deemed reliable for appetite research [14].

Using visual analogue scales many studies have demonstrated that exercise does not acutely increase appetite and vigorous exercise may lead to a temporary suppression of appetite (for recent reviews of these studies, see Bilski et al. [15] and Martins et al. [16]). This temporary suppression of appetite has been termed 'exercise-induced anorexia' and it leads to a short-term negative energy balance. Due to ghrelin's unique appetite-stimulat- 
Fig. 1. Overview of the major hormonal factors influencing energy balance and their possible interaction with exercise. Also shown are other variables affecting energy balance including environmental and individual factors. $\mathrm{CCK}=$ Cholecystokinin; GLP-1 = glucagon-like peptide-1; $\mathrm{OXM}=$ oxyntomodulin; PYY = peptide $\mathrm{YY}$; PP = pancreatic polypeptide. For further explanation see text.

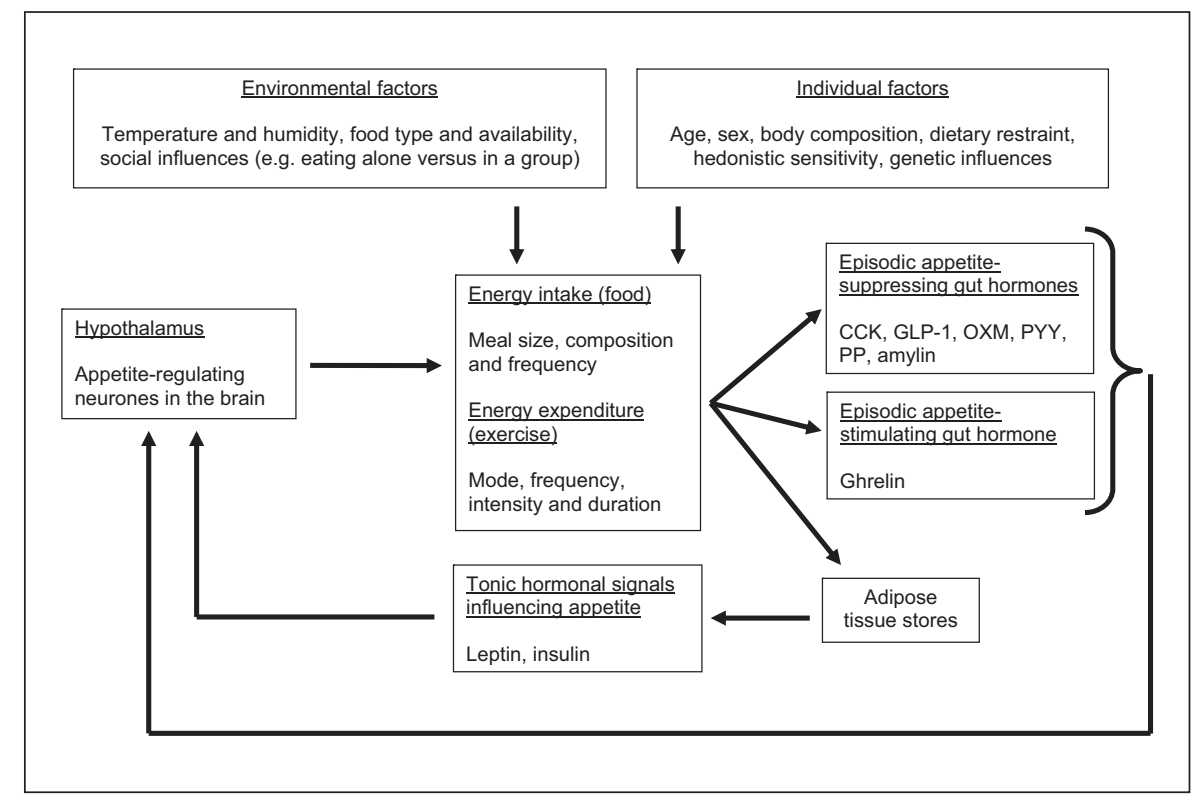

ing properties studies have been conducted to assess whether exercise-induced anorexia is related to lowered concentrations of ghrelin. Initially this did not appear to be the case because several studies observed that ghrelin concentrations were unaffected by acute bouts of exercise $[17,18]$. However, these studies measured total ghrelin concentrations whereas more recent studies have shown that acylated ghrelin (the form of ghrelin thought to be responsible for appetite stimulation; for further details, see Chen et al. [7] and Stengel et al. [8]) is suppressed during running $[19,20]$ and during resistance exercise [20]. These suppressions of acylated ghrelin appear to be transient; lasting for an hour or so after exercise and it is possible that they play a role in exercise-induced anorexia. However, few significant correlations were observed between acylated ghrelin and hunger in these studies [19, 20] and it is therefore questionable as to whether exerciseinduced changes in acylated ghrelin directly influence hunger.

Aside from ghrelin, recent studies have examined episodic gut hormones involved in appetite suppression to assess whether they may contribute to exercise-induced anorexia. Most attention has focused on PYY since this hormone is known to have strong appetite-suppressing effects [21]. Several studies have reported that plasma PYY concentrations are increased during aerobic exercise both in lean $[20,22,23]$ and obese [24] participants. Broom et al. [20] provided standardised meals to their participants 1 and $4 \mathrm{~h}$ after they had completed a 1-hour run. Plasma PYY responses remained elevated for up to $5 \mathrm{~h}$ after exercise in comparison with responses on a resting control trial. Some studies have also examined GLP-1 and $\mathrm{PP}$ responses to aerobic exercise and concentrations of these hormones are also increased during and for at least 30-60 min after exercise [22-24]. In contrast, plasma PYY concentrations were unaffected by resistance exercise in one recent study [20].

Many of the studies described here have involved male participants and there is some evidence that responses may differ in females compared with males. This evidence has been reviewed recently by Hagobian and Braun [25]. In one of their own studies which directly compared males and females they observed compensatory increases in acylated ghrelin in women but not men after 4 days of exercise training designed to induce an energy deficit. Differences in the insulin response to a meal tolerance test after 4 consecutive days of exercise training (approximately 80-90 min of exercise per day) were also observed between males and females indicating a tendency for lower insulin concentrations in women [26]. In another study, leptin concentrations were lowered in response to 12 weeks of exercise training in women but not in men [27]. All of these differences suggest a tendency for appetite to be stimulated by exercise in women in contrast with men. This may explain why some studies have found exercise training to be more effective for fat loss in men than women consuming ad libitum diets [28]. A possible explanation for these differences may be the necessity for 
women to maintain sufficient body fat stores for reproductive success although further research is required before definitive conclusions can be drawn.

\section{Acute Effects of Exercise on Food Intake}

Although changes in appetite and in appetite-regulating hormones have been noted during and after exercise, it does not necessarily follow that food intake will change. To assess whether or not this is the case food intake must be monitored directly - either overtly or covertly. This can be problematic because individuals may alter their food intake if they know or suspect they are being monitored and their appetites may be influenced by the foods they are offered and the testing environment, e.g. being in a laboratory rather than a restaurant! This can confound the findings from exercise studies. (For a comprehensive discussion of the methodological issues inherent when measuring food intake, the reader is referred to Blundell et al. [13].)

The most common method for assessing the acute influence of exercise on food intake is the ad libitum buffet meal. Usually a selection of everyday foods is offered and it is important that these are palatable to participants, otherwise a low energy intake may be observed simply because participants do not like the food on offer. This limitation may be overcome by checking the food preferences of participants in advance. Despite the inherent limitations, at least one study has concluded that ad libitum buffet meals are reproducible, i.e. when they are consumed by the same individuals on 2 separate occasions, the energy intake is highly correlated [29]. It is worth noting though that for some individuals there can be a large variation in the energy intake consumed on 2 separate occasions despite identical feeding conditions. The likelihood of this happening may be reduced by standardising dietary intake prior to assessing ad libitum intake [29].

The majority of exercise studies employing buffet meals have observed no change in energy intake after acute bouts of exercise. One review found that only $19 \%$ of intervention studies report an increase in energy intake after exercise; $65 \%$ show no change and $16 \%$ show a decrease [30]. The lack of change in energy intake in response to an acute bout of exercise has been confirmed in two recent studies, one involving a 90 -min treadmill run [31] and the other involving a 60-min brisk walk [32]. In the former study, energy intake was not significantly altered in the $22.5 \mathrm{~h}$ after running (several meals were provided during this time) despite an average energy expen- diture of 5,324 kJ (1,273 kcal) during the run. Consistent with these findings, acylated ghrelin was not significantly altered after exercise in either study (although acylated ghrelin was suppressed during exercise in the running study). A limitation of most studies examining the acute effects of exercise on food intake has been the relatively short observation period after completion of exercise (usually only a few hours). However, some studies have assessed food intake responses over longer periods as discussed in the next section.

For those required to perform in extreme environments it is important to know how food intake is affected so that compensatory adjustments can be made to optimise nutrition. Few studies have assessed the effects of different environmental conditions on food intake but some evidence is available. Boyer and Blume [33] observed that energy intake, fat absorption and body weight all decreased in Caucasian participants ascending to high altitude as part of the 1981 American Medical Research Expedition to Everest (interestingly decreases in body weight did not occur in the Sherpa guides who habitually reside at high altitude). These findings suggest an anorexic effect of hypoxia and this suggestion is supported by the findings of a recent study which observed significant reductions in food intake and weight and a significant increase in plasma leptin (though no change in ghrelin) in 20 obese males subjected to hypobaric hypoxia $(2,650 \mathrm{~m})$ for 1 week [34]. Similarly there is evidence to suggest that food intake is reduced after exercise in hot environments [35]. This is not necessarily due to dehydration because dehydration in the absence of exercise (i.e. via a sauna) does not suppress hunger or food intake [36]. Finally, exercising in cold water has been shown to increase food intake in the immediate $(80-\mathrm{min})$ post-exercise period, suggesting that energy intake may need to be increased when performing for prolonged periods in cold environments, certainly if immersed in cold water [37].

\section{Exercise Training, Appetite and Food Intake}

Studies examining the effects of acute bouts of exercise are informative, but exercise training studies are required to determine the long-term effects of exercise on appetite, food intake and weight control. Although literature is not abundant in this area, a few studies are available. Jones et al. [38], for example, reported a significant increase in fasting plasma PYY concentrations after 32 weeks of exercise training in overweight male and female adolescents 
who experienced a significant decrease in percentage of body fat. Similarly, Roth et al. [39] observed a significant increase in fasting plasma PYY concentrations in obese children who were successful at losing weight after a 1-year diet and exercise intervention and Martins et al. [40] observed a tendency for higher postprandial PYY concentrations in overweight/obese men and women after a 12-week exercise intervention. These findings suggest improved satiety after weight/fat loss induced by exercise training.

Conflicting findings have been reported with respect to exercise training and ghrelin. Hagobian et al. [41] found that area-under-the-curve values for total ghrelin were unchanged during 3 days of overfeeding in sedentary conditions but declined when overfeeding was combined with exercise suggesting a reduction in appetite. Leidy et al. [42] observed increases in fasting total ghrelin concentrations in exercisers who lost weight after a 3 -month intervention but no change in ghrelin in weightstable exercisers. Similarly increases in post prandial acylated ghrelin concentrations have been observed in lean and obese adolescents after 5 consecutive days of exercise training [43]. In contrast, acylated ghrelin was unchanged after a 12-week exercise intervention, which resulted in significant weight and fat loss in overweight Korean children [44]. It is difficult to come to any firm conclusions on the basis of these studies. The discrepancies are possibly explained by differences in the participant groups (i.e. adolescents vs. adults), the duration of exercise training (i.e. a few days up to 1 year) and the fact that some studies measured total ghrelin while others measured acylated ghrelin. It should also be noted that changes in ghrelin after exercise training and weight loss may be balanced by opposing changes in satiety hormones such that an increased drive to eat in a fasting state may be matched by an increased satiety response to a meal as reported recently [40].

Most studies examining the effects of exercise training on ad libitum energy intake are limited by the fact that food intake is self-reported, but there is little alternative if participants are to be observed in their natural environment rather than under laboratory conditions. James Stubbs and colleagues have completed 2 interesting studies in this regard. One study involved 6 lean women completing three 7-day trials: (1) control (no exercise); (2) medium exercise level (1.9 MJ day ${ }^{-1}$ ); (3) high exercise level (3.4 MJ day $\left.{ }^{-1}\right)$. A significant compensation in energy intake was observed, but this only amounted to $33 \%$ of the energy expenditure due to exercise; hence the women lost a small but significant amount of weight on both exercise trials [45]. In a second study, 6 lean men were confined to a whole-body indirect calorimeter for two 7-day periods. In both periods, food was available ad libitum, but men were moderately active during one period and sedentary during the other. Energy intake and hunger were unchanged by the imposition of the sedentary regime causing the men to attain a positive energy balance and increased fat storage [46]. Similar findings were obtained by Woo and colleagues who covertly monitored food intake over 19 days [47] and 57 days [48] in obese women voluntarily confined to hospital. No compensatory increase in energy intake was detected despite increased energy expenditure through daily walking. Collectively these findings suggest that increased physical activity causes at best a partial increase in energy intake, while reduced levels of exercise will not necessarily be accompanied by reduced energy intake.

If exercise does not induce a strong and full compensatory drive to increase food intake, one might ask why many individuals find long-term weight loss difficult. This may be explained by a discontinuation of exercise when early enthusiasm begins to wane or even a compensatory decrease in habitual physical activity at a time when exercise levels are concurrently being increased through structured exercise as has been shown recently [49]. Finally, the study of Caudwell et al. [50] is a reminder of the limitations of generalising based on group data. These researchers observed a large variability in weight loss over a 12 -week period during a closely supervised programme in 58 obese men and women completing 5 exercise sessions per week (2,092 kJ energy expenditure per session). This variability ranged from a loss of $14.7 \mathrm{~kg}$ to a gain of $2.7 \mathrm{~kg}$. Experimenter observation of ad libitum food intake during lunch and dinner and via snacks (at baseline, 4, 8 and 12 weeks) suggested increased food intake and reduced intake of fruits and vegetables in those who failed to lose meaningful weight.

\section{Implications for Sportsmen and Women}

What are the implications of work on exercise and appetite for athletes wishing to lose weight? Unfortunately research relating to exercise and appetite hormones is still in its infancy and further investigation is required before definitive advice can be given. What can be said with some confidence is that for most individuals vigorous exercise causes a transient suppression of appetite and does not automatically increase food intake - at least not suf- 
ficiently to fully compensate for the energy expended in exercise. Hence the fear that exercise may cause overeating [51] appears to be unfounded although there may be some individuals who are more likely to experience increased hunger with exercise and some evidence suggests a greater risk of this in women [25]. The lack of a compensatory increase in food intake after exercise may be due to the lack of a compensatory increase in ghrelin after exercise and/or a prolonging of satiety due to exerciseinduced increases in appetite-suppressing hormones such as PYY and GLP-1, but the true significance of these hormonal responses requires further in-depth study to definitively link exercise-induced changes in appetite hormones with changes in appetite and food intake. If such links are confirmed, it may be that strategies can be developed for weight loss by the appropriate timing of exercise. For example, exercise completed in the postprandial period may extend the satiating effects of a meal, as has been suggested recently [52], but far more research is required to determine if such strategies enhance weight loss. Future research will also need to try and tease out why some individuals respond differently to exercise compared with others and how appetite responses to exercise can be predicted for a given individual. Another avenue of research which warrants further study is the extent to which changes in appetite-regulating hormones may be useful markers of training stress as has been muted recently [53].

\section{Summary and Conclusions}

Much has been learned in recent years about how exercise influences appetite, appetite-regulating hormones, food intake and weight. There is evidence that exercise can have a beneficial influence on appetite and appetiteregulating hormones facilitating a negative energy balance and weight loss. It should be recognised that appetite and food intake may be affected by a host of factors including age (e.g. children vs. adults vs. older adults), sex (male vs. female), body composition (obese vs. lean), physical activity levels (habitually active vs. habitually inactive), environmental factors (e.g. environmental temperature, eating alone vs. eating in groups), individual differences (e.g. some individuals are restrained eaters while others eat until satisfied) and also the palatability of available food. These factors are likely to influence the balance between hedonistic and homeostatic controls and make it difficult to generalise with confidence. Nevertheless, the wealth of available research and the speed at which knowledge is advancing in this area bring hope that improved strategies for weight control may be on the horizon.

\section{Disclosure Statement}

The author declares no conflict of interest.

\section{References}

1 Benelam B: Satiation, satiety and their effects on eating behaviour. Br Nutr Found Nutr Bull 2009;34:126-173.

2 Delzenne N, Blundell J, Brouns F, Cunningham K, De Graaf K, Erkner A, Lluch A, Mars M, Peters HPF, Westerterp-Plantenga M: Gastrointestinal targets of appetite regulation in humans. Obes Rev 2010;11:234-250.

3 Kara E, Batterham RL: The role of gut hormones in the regulation of body weight and energy homeostasis. Mol Cell Endocrinol 2010;316:120-128.

4 Neary MT, Batterham RL: Gut hormones: implications for the treatment of obesity. Pharmacol Ther 2009;124:44-56.

5 Druce MR, Neary NM, Small CJ, Milton J, Monteiro M, Patterson M, Ghatei MA, Bloom SR: Subcutaneous administration of ghrelin stimulates energy intake in healthy lean human volunteers. Int J Obes 2006;30: 293-296.
6 Druce MR, Wren AM, Park AJ, Milton JE, Patterson M, Frost G, Ghatei MA, Small C, Bloom SR: Ghrelin increases food intake in obese as well as lean subjects. Int J Obes 2005; 29:1130-1136.

-7 Chen CY, Asakawa A, Fujimiya M, Lee SD, Inui A: Ghrelin gene products and the regulation of food intake and gut motility. Pharmacol Rev 2009;61:430-481.

-8 Stengel A, Goebel M, Wang L, Taché Y: Ghrelin, des-acyl ghrelin and nesfatin-1 in gastric X/A-like cells: role as regulators of food intake and body weight. Peptides 2010;31:357-369.

$\checkmark 9$ Adachi S, Takiguchi S, Okada K, Yamamoto K, Yamasaki M, Miyata H, Nakajima K, Fujiwara $\mathrm{Y}$, Hosoda $\mathrm{H}$, Kangawa K, Mori M, Doki Y: Effects of ghrelin administration after total gastrectomy: a prospective, randomized, placebo-controlled phase II study. Gastroenterology 2010;138:1312-1320.
10 Adams CE, Greenway FL, Brantley PJ: Lifestyle factors and ghrelin: critical review and implications for weight loss maintenance. Obes Rev 2010, DOI: 10.1111/j.1467-789X. 2010.00776.x

11 Borer KT: Nonhomeostatic control of human appetite and physical activity in regulation of energy balance. Exerc Sport Sci Rev 2010;38:114-121.

12 Neary MT, Batterham RL: Gaining new insights into food reward with functional neuroimaging; in Langhans W, Geary N (eds): Frontiers in Eating and Weight Regulation. Forum Nutr. Basel, Karger, 2010, vol 63, pp 152-163.

13 Blundell J, de Graaf C, Hulshof T, Jebb S, Livingstone B, Lluch A, Mela D, Salah S, Schuring E, van der Knaap H, Westerterp M: Appetite control: methodological aspects of the evaluation of foods. Obes Rev 2010;11:251270. 
14 Flint A, Raben A, Blundell JE, Astrup A: Reproducibility, power and validity of visual analogue scales in assessment of appetite sensations in single test meal studies. Int J Obes 2000;24:38-48.

15 Bilski J, Teległów A, Zahradnik-Bilska J, Dembiński A, Warzecha Z: Effects of exercise on appetite and food intake regulation. Med Sport 2009;13:82-94.

16 Martins C, Morgan L, Truby H: A review of the effects of exercise on appetite regulation: an obesity perspective. Int J Obes 2008; 32 : 1337-1347.

-17 Burns SF, Broom DR, Miyashita M, Mundy C, Stensel DJ: A single session of treadmill running has no effect on plasma total ghrelin concentrations. J Sports Sci 2007;25:635642.

${ }_{18}$ Dall R, Kanaley J, Hansen TK, Møller N, Christiansen JS, Hosoda H, Kangawa K, Jørgensen JOL: Plasma ghrelin levels during exercise in healthy subjects and in growth hormone-deficient patients. Eur J Endocrinol 2002;147:65-70.

$\checkmark 19$ Broom DR, Batterham RL, King JA, Stensel DJ: Influence of resistance and aerobic exercise on hunger, circulating levels of acylated ghrelin and peptide YY in healthy males. Am J Physiol Regul Integr Comp Physiol 2009; 296:R29-R35.

-20 Broom DR, Stensel DJ, Bishop NC, Burns SF, Miyashita M: Exercise induced suppression of acylated ghrelin in humans. J Appl Physiol 2007;102:2165-2171.

21 Neary MT, Batterham RL: Peptide YY: food for thought. Physiol Behav 2009;97:616-619.

-22 Martins C, Morgan LM, Bloom SR, Robertson MD: Effects of exercise on gut peptides, energy intake and appetite. J Endocrinol 2007;193:251-258.

-23 Ueda S, Yoshikawa T, Katsura Y, Usui T, Fujimoto S: Comparable effects of moderate intensity exercise on changes in anorectic gut hormone levels and energy intake to high intensity exercise. J Endocrinol 2009;203:357364.

-24 Ueda S, Yoshikawa T, Katsura Y, Usui T, Nakao H, Fujimoto S: Changes in gut hormone levels and negative energy balance during aerobic exercise in obese young males. J Endocrinol 2009;201:151-159.

25 Hagobian TA, Braun B: Physical activity and hormonal regulation of appetite: sex differences and weight control. Exerc Sport Sci Rev 2010;38:25-30.

-26 Hagobian TA, Sharoff CG, Stephens BR, Wade GN, Silva JE, Chipkin SR, Braun B: Effects of exercise on energy-regulating hormones and appetite in men and women. Am J Physiol Regul Integr Comp Physiol 2009; 296:R233-R242.
27 Hickey MS, Houmard JA, Considine RV, Tyndall GL, Midgette JB, Gavigan KE, Weidner ML, McCammon MR, Israel RG, Caro JF: Gender-dependent effects of exercise training on serum leptin levels in humans. Am J Physiol Endocrinol Metab 1997; 272:E562-E566.

28 Donnelly JE, Hill JO, Jacobsen DJ, Potteiger J, Sullivan DK, Johnson SL, Heelan K, Hise M, Fennessey PV, Sonko B, Sharp T, Jakicic JM, Blair SN, Tran ZV, Mayo M, Gibson C, Washburn RA: Effects of a 16-month randomized controlled exercise trial on body weight and composition in young, overweight men and women. The Midwest Exercise Trial. Arch Intern Med 2003;163:13431350.

29 Gregersen NT, Flint A, Bitz C, Blundell JE, Raben A, Astrup A: Reproducibility and power of ad libitum energy intake assessed by repeated single meals. Am J Clin Nutr 2008;87:1277-1281.

-30 Blundell JE, King NA: Physical activity and regulation of food intake: current evidence. Med Sci Sports Exerc 1999;31:S573-S583.

31 King JA, Miyashita M, Wasse LK, Stensel DJ: Influence of prolonged treadmill running on appetite, energy intake and circulating concentrations of acylated ghrelin. Appetite 2010;54:492-498.

32 King JA, Wasse LC, Broom DR, Stensel DJ: The influence of brisk walking on appetite, energy intake and plasma acylated ghrelin. Med Sci Sports Exerc 2010;42:485-492.

33 Boyer SJ, Blume FD: Weight loss and change in body composition at high altitude. J Appl Physiol 1984;57:1580-1585.

34 Lippl FJ, Neubauer S, Schipfer S, Lichter N, Tufman A, Otto B, Fischer R: Hypobaric hypoxia causes body weight reduction in obese subjects. Obesity 2010;18:675-681.

35 Shorten AL, Wallman KE, Guelfi KJ: Acute effect of environmental temperature during exercise on subsequent energy intake in active men. Am J Clin Nutr 2009;90:12151221.

36 Westerterp-Plantenga MS, Verwegen CRT, Ijedema MJW, Wijckmans NEG, Saris WHM: Acute effects of exercise or sauna on appetite in obese and non-obese men. Physiol Behav 1997;62:1345-1354.

37 White LJ, Dressendorfer RH, Holland E, McCoy SC, Ferguson MA: Increased caloric intake soon after exercise in cold water. Int $\mathrm{J}$ Sport Nutr Exerc Metab 2005;14:38-47.

38 Jones TE, Basilio JL, Brophy PM, McCammon MR, Hickner RC: Long-term exercise training in overweight adolescents improves plasma peptide YY and resistin. Obesity 2009;17:1189-1195.

-39 Roth CL, Enriori PJ, Harz K, Woelfle J, Cowley MA, Reinehr T: Peptide YY is a regulator of energy homeostasis in obese children before and after weight loss. J Clin Endocrinol Metab 2005;90:6386-6391.
40 Martins C, Kulseng B, King NA, Holst JJ, Blundell JE: The effects of exercise-induced weight loss on appetite-regulated peptides and motivation to eat. J Clin Endocrinol Metab 2010;95:1609-1616.

41 Hagobian TA, Sharoff CG, Braun B: Effects of short-term exercise and energy surplus on hormones related to regulation of energy balance. Metab Clin Exp 2008;57:393-398.

42 Leidy HJ, Gardner JK, Frye BR, Snook ML, Schuchert MK, Richard EL, Williams NI: Circulating ghrelin is sensitive to changes in body weight during a diet and exercise program in normal-weight young women. J Clin Endocrinol Metab 2004;89:2659-2664.

43 Mackelvie KJ, Meneilly GS, Elahi D, Wong ACK, Barr SI, Chanoine JP: Regulation of appetite in lean and obese adolescents after exercise: role of acylated and desacyl ghrelin. J Clin Endocrinol Metab 2007;92:648-654.

$\checkmark 44$ Kim JK, Leet S, Kim TW, Kim HH, Jeon TY, Yoon YS, Oh SW, Kwak H, Lee JG: Effects of exercise-induced weight loss on acylated and unacylated ghrelin in overweight children. Clin Endocrinol 2008;68:416-422.

45 Stubbs RJ, Sepp A, Hughes DA, Johnstone AM, King N, Horgan G, Blundell JE: The effect of graded levels of exercise on energy intake and balance in free-living women. Int $\mathrm{J}$ Obes 2002;26:866-869.

46 Stubbs RJ, Hughes DA, Johnstone AM, Horgan GW, King N, Blundell JE: A decrease in physical activity affects appetite, energy, and nutrient balance in lean men feeding ad libitum. Am J Clin Nutr 2004;79:62-69.

47 Woo R, Garrow JS, Pi-Sunyer FX: Effect of exercise on spontaneous calorie intake in obesity. Am J Clin Nutr 1982;36:470-477.

48 Woo R, Garrow JS, Pi-Sunyer FX: Voluntary food intake during prolonged exercise in obese women. Am J Clin Nutr 1982;36:478484.

49 Manthou E, Gill JMR, Wright A, Malkova D: Behavioural compensatory adjustments to exercise training in overweight women. Med Sci Sports Exerc 2010;42:1221-1228.

50 Caudwell P, Hopkins M, King NA, Stubbs RJ, Blundell JE: Exercise alone is not enough: weight loss also needs a healthy (Mediterranean) diet. Public Health Nutr 2009;12: 1663-1666.

51 Cloud J: Why exercise won't make you thin. Time, Aug 9, 2009. http://www.time.com/ time/health/article/0,8599,1914857-1,00. html (accessed October 19, 2010).

52 Cheng MH, Bushnell D, Cannon DT, Kern M: Appetite regulation via exercise prior or subsequent to high-fat meal consumption. Appetite 2009;52:193-198.

53 Jürimäe JA, Mäestu J, Jürimäe T, Mangus B, von Duvillard SP: Peripheral signals of energy homeostasis as possible markers of training stress in athletes: a review. Metabolism 2010, DOI: 10.1016/j.metabol.2010.02. 009 . 